\title{
ROAD TRANSPORT ACCIDENTS IN THE FOCUS OF PUBLIC HEALTH IN BULGARIA
}

\author{
D. Dimitrova* \\ Department of Preventive Medicine, FPH, MU-Sofia, Bulgaria
}

\begin{abstract}
The greatest number of disasters in Bulgaria are road transport accidents (RTA). Annually, according to data of the Ministry of Interior, more than 7000 RTAs are registered. Not only socio-economic, but also health consequences for society arise. The purpose of the study is to investigate and analyze the medical casualties among the population of the country as a result of RTA. Methods. Statistical survey on RTA on the territory of the country for the period of 1951-2017. Results. The data indicate that the most common causes of fatal accidents with fatalities in our country are incorrect actions of the driver - 95\% and about 2/3 of the RTA are during the day. The number of victims is about 10000 annually, and about 700 deaths. Conclusions. During RTA the number of people killed per 1 million population is 102 people. According to the national strategy for improving the road safety in Bulgaria for the period 2011-2020, the number of people killed in road accidents should decrease by 50 per cent and should not exceed 380 people in 2020, and the number of the seriously injured - should not exceed 6,300 people.
\end{abstract}

Key words: road transport accidents; casualties; public health; Bulgaria

\section{INTRODUCTION}

The greatest number of disaster situations in Bulgaria are road transport accidents (RTA). Annually, according to data of the Ministry of Interior, more than 7000 RTAs are registered. (1-7) Not only socio-economic, but also health consequences (8-14) for society arise. Annually, over 1.3 million people die in road accidents. (7) For the last 10 years, 10,000 people have died in the country - the population of Sopot or Bansko, and the number of people injured is equal to the population in Pernik. (1, 2, 3,13) By the number of people killed on the road, Bulgaria ranked third after Latvia - 103 per 1 million, and Romania - 100 per 1 million. Malta suffered the least - 26 victims per 1 million, the Netherlands and the UK - 28 per 1 million. $(1,3,7)$

\section{PURPOSE}

The aim of the study is to investigate and analyze the medical casualties among the population of the country as a result of RTA.

\footnotetext{
*Correspondence to: Dimitrova D., Department of Preventive Medicine, FPH, MU-Sofia, Bulgaria, Bulgaria, 1527, Sofia, Byalo more st., 8, Tel. 0889256810
}

\section{METHODS}

Data from the NSI, the Ministry of Interior and the Ministry of Health for the occurrence of road accidents on the territory of the country are applied and analyzed. Scope - road accidents on the territory of the country. The analysis of medical casualties covers the period 1951-2017 with an emphasis on the past five years. Statistical units of the study medical casualties. Unit of measure - number of victims and relative share. A descriptive, retrospective and comparative analysis of the medical casualties because of RTA was made among the population in the country.

\section{RESULTS}

The data indicate that the most common main causes of fatal accidents with fatalities in our country are incorrect actions of the driver 95\% (Figure 1).

The leading cause of crash is the incorrect judgment of the driver (about 95\%), and of them at an inappropriate speed - above 1/3. (1, $3,5-7,10)$ The study indicates that over $40 \%$ of the cause is determined by bad roads. Nearly $2 / 3$ of road accidents are during the day. (Table 1) (1, 4-6) 


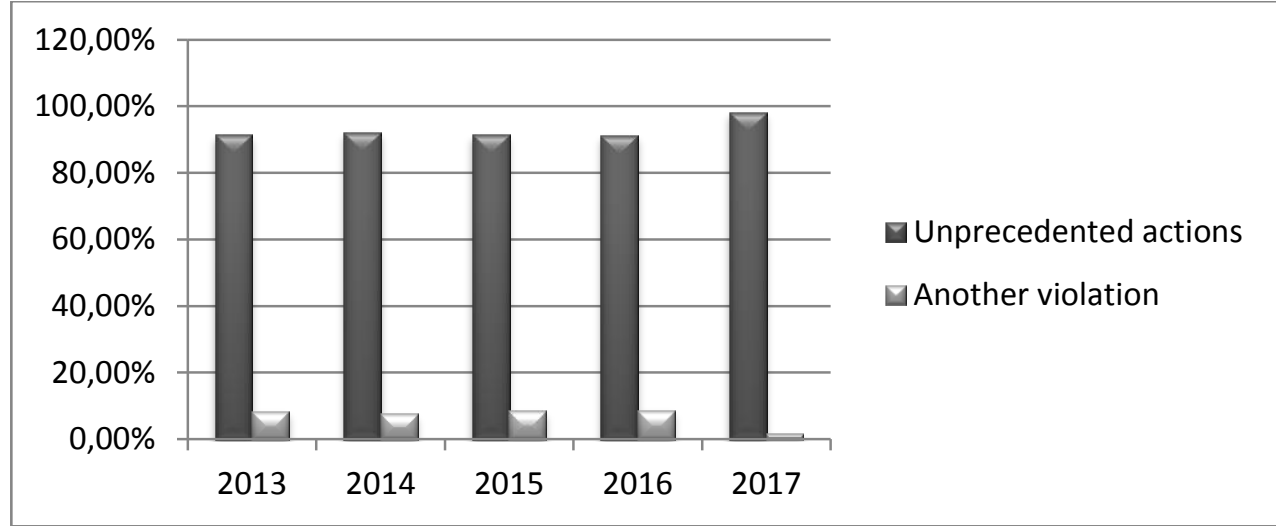

Figure 1. RTA according to the reason for the period 2013-2017

Table 1. Accidents (RTA), deaths and injuries according to light - day and night (according to MoI data)

\begin{tabular}{|l|l|l|l|l|l|l|l|l|l||l|l|l||l|l|l|}
\cline { 2 - 14 } \multicolumn{1}{c|}{} & \multicolumn{3}{c||}{2013} & \multicolumn{3}{c|}{2014} & \multicolumn{3}{c||}{2015} & \multicolumn{3}{c|}{2016} & \multicolumn{3}{c|}{2017} \\
\hline & & & & & & & & & & & & & & & \\
& RTA & K & MC & RTA & K & MC & RTA & K & MC & RTA & K & MC & RTA & K & MC \\
\hline DL & 36564 & 361 & 6385 & 5127 & 392 & 6314 & 5183 & 437 & 6364 & 5420 & 469 & 6826 & 5085 & 432 & 6311 \\
\hline AL & 6218 & 44 & 1083 & 936 & 65 & 1117 & 955 & 75 & 1212 & 856 & 40 & 1097 & 822 & 47 & 1058 \\
\hline
\end{tabular}

RTA - road transport accidents

The number of people injured during the day is over 6000 per year, and for the last five years a total of about 33000 . The average number of people killed per day is about 400 people per day, and about 55 in the middle of the night. (Table 1) The number of victims annually is about 10,000 (Figures 2 and 3), and the death rate is about 700 (Figure 3). (1, 2, 4-6, 9)

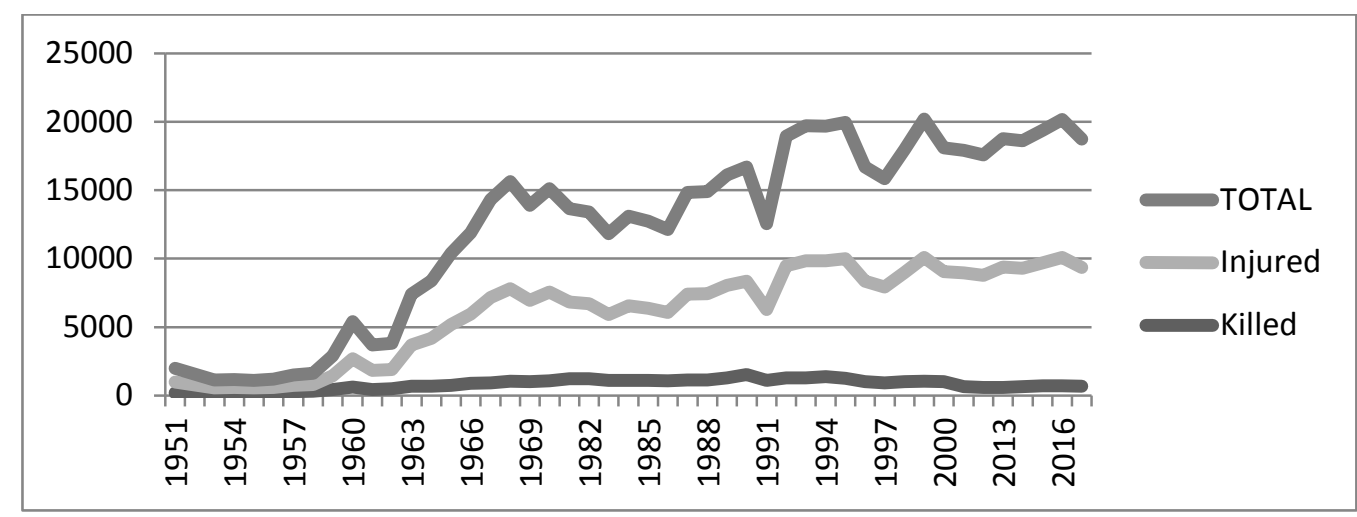

Figure 2. Victims of road accidents for the period 1951-2017

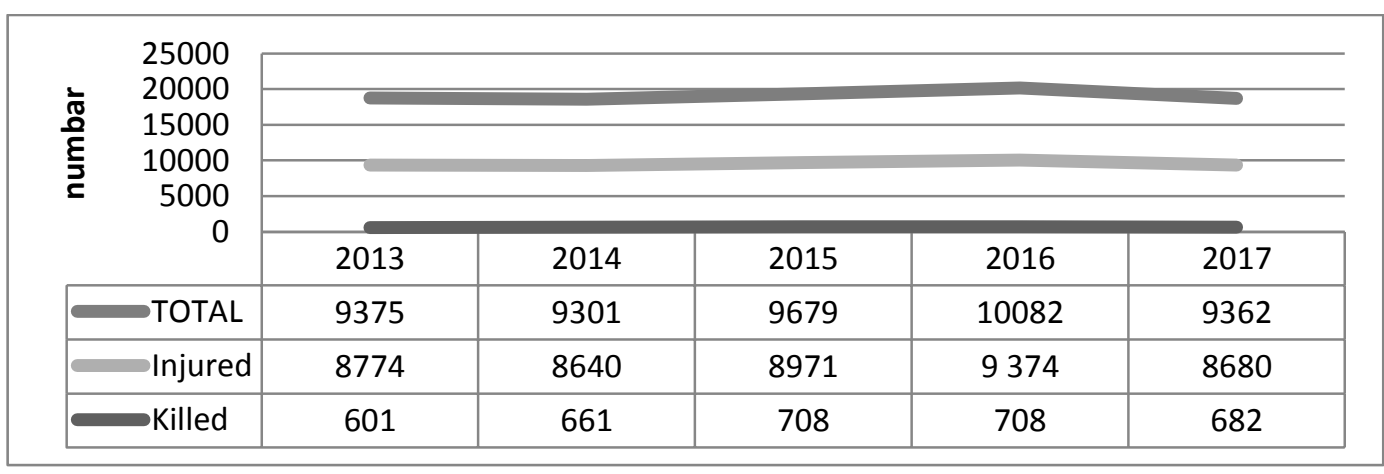

Figure 3. Victims of road accidents for the period 2013-2017 
Total for the past five years have affected more than 50000 . According to the survey data, the largest number of road accidents are reported on Friday. This is due to the increased traffic to the province. By district, the largest share of road accidents was reported in Sofia-city and Sofia region. Average for one year - 1200 . Second is the Plovdiv region - almost 1/3 less, and the third is Stara Zagora region - around $2 / 3$ less.

Road traffic accidents are a major cause of the deaths of young people between 10 and 24 years of age. (1) The average deaths are as follows: about 260 - motor vehicle drivers, about 240 - passengers, over 170 - pedestrians. The largest share among pedestrians on average $(56.6 \%)$ are people over the age of 64 followed by those in the age group 25-64 (about 30\%). Children up to 17 years - nearly 40 people. $(1,9)$

\section{DISCUSSION}

During RTA the number of people killed in the country per 1 million population is 102 people. This places our country far away from countries like England, Sweden and the Netherlands where deaths from RTA are nearly two times lower. According to the national strategy for improving the road safety in Bulgaria for the period 2011-2020, the number of people killed in road accidents should decrease by 50 per cent and should not exceed 380 people in 2020 , and the number of the seriously injured - should not exceed 6,300 people. (13)

Updating the road map for the most dangerous roads in the country is a necessary step for risk prevention. (by the Ministry of Interior) Improving the knowledge and literacy of pedestrians as participants in the movement is key to risk prevention as well. (by the Bulgarian Red Cross) Preparation of the students in the various medical specialties for crash activities and enhancing postgraduate education for healthcare professionals in road accidents are important tasks in the education system. (by the MH) Faster and easier transportation of the victims of traffic accidents is the air medical transport.

\section{CONCLUSION}

Traffic safety is a shared responsibility. The road traffic process is a continuous interaction between three major factors that determine the traffic and its safety - the behavior of road users, the safety of road infrastructure and the fleet. Much of the road traffic accident is preventable and reflects these factors, as well as the condition of doctors 'and doctors' medical care. To prevent preconditions for crash, it is necessary to initiate and coordinate the efforts of all state institutions, ministries and agencies, nongovernmental organizations, the ESS112 and society.
Abbreviations
RTA - Road Transport Accidents
MoI - Ministry of Interior
NSI - National Statistical Institute
MH - Ministry of Health
HL - Health Law

\section{REFERENCES}

1. Health Law, Prom., SG (DV), no. 70 of 10.08.2004, in force since 1.01.2005, amend. and supplements, nos. 18 of 27.02.2018, in force as of 27.02.2018.

2. MoI data of RTA in Bulgaria, 2018

3. RTA, Promulgated SG(DV), No. 20 of 5.03.1999, in force since 1.09.1999, amend. and add., no. 77 of 26.09.2017, in force as of 26.09.2017.

4. Strategy for the development of the transport system of the Republic of Bulgaria until 2020, MTITC, march 2010

5. T2 report, crashes (victims), perished and injured period 2013-2017, MI, 2017

6. T11 report, road traffic accidents (victims), dead and injured, period 2013-2017, Ministry of Interior, 2017.

7. T43 report, crashes (victims), perished and injured, period 2013-2017, MI, 2017

8. Excessive speed and improper overtaking are still the most common causes of road death, the Bulgarian Association of Casualties, 2017

9. Information materials, Bulgarian Association of Victims of Catastrophes, 2017

10.MH data of victims of RTA in Bulgaria, 2018

11.NSI data of RTA in Bulgaria, 2018

12. Road Map of the Most Dangerous Roads in Bulgaria, Ministry of Interior, 2017

13. Statistical analysis by the European Commission, the State Committee on Road Safety, 2017

14.WHO data of RTA, 2018 